\title{
Ley, Derecho y paz social: el caso de la tolerancia
}

\author{
Antonio-Carlos Pereira Menaut ${ }^{1}$ \\ Carolina Pereira Sáez ${ }^{2}$
}

\begin{abstract}
Resumen La tolerancia no está hoy de moda, por lo que hay que recordar qué es realmente. Además de ello, mostramos cómo es: asistemática, no estrictamente racional, pluriforme, e imprescindible para la vida social. También estudiamos la relación que tiene con el Derecho (que no es unívoca), así como los factores ambientales favorables o desfavorables.

Palabras Clave: Tolerancia, derecho, ley.

Abstract: Toleration is not a quite fashionable notion today. Thus, first of all we must remember what it really is. Besides that, we will try to show how its inner frame is: it is not very systematic, nor strictly rational, rather protean ? and essential for social life to run smoothly. We study its relationship with Law (another concept with several meanings and several sources), as well as the favourable and disfavourable environmental factors that can affect toleration.
\end{abstract}

Keywords: Toleration, Law, Statute Law.

\section{Introducción}

Es innecesario decir que la tolerancia es importante para la paz social y la convivencia. En nuestra vida social real, la estricta justicia no basta para solucionar (y menos cicatrizar) los problemas difíciles, por eso necesitamos también que estén difundidas algunas actitudes como el perdón, sin excluir el olvido, la equidad en la aplicación del derecho y la tolerancia. Especialmente en su versión "justiciera", que la considera sobre todo como retribución, la justicia linda con la venganza, por lo que puede producir la respuesta de una nueva venganza, lo que más de una vez ha dado lugar a una espiral de violencia. Los problemas de Sudáfrica y el Ulster se han ido solucionando a base de no aspirar a la estricta justicia, mientras que en el caso del terrorismo vasco el enfoque ha sido más legalista y "justiciero", volviendo así más difícil la cicatrización de un problema ciertamente grave, pero que realidad de una magnitud sensiblemente menor que los otros dos mencionados.

Este artículo intenta iluminar tres problemas:

- el mal entendimiento de la tolerancia, así como la realidad de que, de facto, estamos en una sociedad intolerante, incluso marcadamente intolerante a veces; cualquiera que sea la impresión superficial o la "verdad oficial"

- puntos clave de la moderna visión jurídica y política que favorecen o perjudican la tolerancia

- los límites del derecho (y en particular de la ley) a la hora de abarcar la tolerancia

\section{Recordatorios}

Primero. La tolerancia es muy antigua, mucho más que Locke o, por supuesto, Kant. Algunos autores hacen depender demasiado la tolerancia del prerrequisito de la autonomía moral kantiana ${ }^{i}$, y, en general, de la Ilustración; aunque Locke, que murió en 1702, no fue propiamente un ilustrado salvo en sentido amplio. La Ilustración

\footnotetext{
${ }^{1}$ Profesor de Derecho Constitucional, U. de Santiago de Compostela, Galicia; <acp.menaut@usc.es>

${ }^{2}$ Profesora de Filosofía del Derecho; U. da Coruña, Galicia; <cpereiras@ udc.es>
} 
contiene sin duda elementos que favorecen la tolerancia, pero igualmente puede ser despótica y poco tolerante. La tolerancia, aunque sin este nombre, es muy anterior: se remonta al indeterminado momento en que alguien captó la imperfección humana, la necesidad de templar la dureza con equidad, las limitaciones de la ley, o la necesidad de tener paciencia con los defectos de los demás para convivir. Aparte del Cristianismo, sin dificultad se pueden rastrear planteamientos tolerantes en la visión aristotélica del hombre y la sociedad, en Roma o en el Imperio Otomano. Éste duró unos 600 años, seis siglos en los que se aplicó la muerte por lapidación en muy pocas ocasiones; además los judíos y los cristianos ortodoxos fueron ampliamente tolerados (de lo contrario, no se explicaría la supervivencia de la religión y el idioma en Grecia). Durante todo el s. XVIII, en el entonces Reino de Galicia, la Inquisición condenó a muerte a un reducidísimo número de personas.

Los grandes imperios, como el romano, el otomano y el británico, practicaron mucho la tolerancia porque no trataron de uniformar sus poblaciones sino de acomodarlas, y la tolerancia es un instrumento muy valioso para 'acomodar sin uniformar'. Similarmente, si en la edad media española no se produjeron demasiadas persecuciones religiosas ni guerras de religión (que luego se producirían en épocas más modernas, con el estado y la Reforma), fue, en buena medida, por la tolerancia.

Segundo. Como no sea para evitar la incorrección política de usar 'intolerancia', la expresión 'tolerancia cero' no tiene sentido, porque la tolerancia siempre es para lo malo o al menos aquello que desaprobamos. Si en algún momento puede darse la 'tolerancia cero' habrá que verlo en cada caso, y nunca será sólo porque la conducta en cuestión sea mala, pues, primero, lo bueno no es objeto de la tolerancia sino de la alabanza, premio o gratitudii; segundo, lo indiferente tampoco necesita ser tolerado, y tercero, el ejercicio de un derecho es derecho, no tolerancia: qui iure suo utitur neminem laedit.

Tercero. Vivimos malos tiempos para la tolerancia. Tras el 11 de Septiembre de 2011 proliferan en Occidente los planteamientos desfavorables a la tolerancia, aunque nadie lo diga así. En los últimos quince años muchos líderes políticos de muchos países han proclamado la 'Guerra total al terrorismo', 'war on terror', 'guerra total a la delincuencia' o incluso al fraude. En realidad, una persona liberalii y constitucionalista debería ser cuidadosa con la palabra total, que por algo es la raíz de 'totalitarismo'. Tony Blair más de una vez dijo "personal lifestyles free, tough on crime" y "pro gay rights, tough on crime", con el resultado de aumentar la intolerancia respecto a los delincuentes pero también respecto de lo políticamente incorrecto en materia de personal lifestyles o gay rights ${ }^{i v}$. Es como decir que seremos completamente intolerantes frente al delito, sin matizar más; una actitud nueva en occidente, donde siempre se distinguía el delito del delincuente y se valoraba cada caso.

\section{Problemas de la tolerancia}

La puesta en práctica de la tolerancia no está libre de todo problema, ni es como aplicar una ciencia exacta. La tolerancia tiene diversas fuentes, facetas y aspectos, que pueden variar de un caso a otro, y en su aplicación habrá siempre una dosis de sentido común y decisión prudencial que no se tomará por evidencia ni por estricta lógica. Vivimos en la era digital, pero la tolerancia pertenece más bien a la analógica, y, como tal, tiene carencias y no es perfecta (ella misma parte de la imperfección), sistemática ni completamente coherente. La tolerancia está más cómoda con el bonus paterfamilias, el 'honrado comerciante', la bona fides, el hombre razonable o the man on the Clapham omnibus ${ }^{v}$ que con el eficiente funcionario, el 
gestor o el optimizador de recursos y ganancias. La tolerancia no tiene una solución para todos los casos; por el contrario, presupone la improbabilidad de que tal cosa exista.

Primer problema. ¿Es la tolerancia contraria a la igualdad? Pues el tolerado parece estar en una posición inferior al que tolera. Pero aunque aparente a primera vista ser desigualitaria, parte de la igualdad humana básica, de que el tolerado, por mal que haga las cosas, es en el fondo igual de respetable que yo, tiene idéntica dignidad básica, y por eso debo tolerarlo. El Imperio Británico en la India toleraba casi todo pero prohibió la incineración de viudas, los sacrificios humanos y el infanticidio. Ciertamente, en ese caso parece haber superioridad moral de unos sobre otros, pero, ¿acaso no es objetivamente cierto que la incineración de viudas o los sacrificios humanos son posturas objetivamente injustificables, aunque sea un poder colonial o no democrático quien los prohíbe? La tolerancia implica la igualdad entre las personas, pero implica también que las posturas y acciones no son iguales, sino unas moralmente mejores que otras. Seguramente había aspectos en que los hindúes eran moralmente superiores a los ingleses, y seguramente los antiguos britanos también practicaron sacrificios humanos antes de los romanos o del Cristianismo, así que en el fondo de su humanidad serían iguales. Si en ese caso concreto hubiera habido igualdad y relativismo, los hindúes habrían seguido con esas costumbres. La tolerancia no es contraria a la igualdad profunda sino que la presupone: uno de sus argumentos es que estamos juzgando a seres humanos iguales a nosotros. Otra explicación del igualitarismo de fondo de la tolerancia es que en la vida todos nosotros seremos unas veces los que toleran y otras los tolerados (esto es así entre las personas pero no entre los países o grupos: por ejemplo, los griegos y los judíos durante el largo imperio otomano fueron siempre los tolerados).

Segundo. La tolerancia no es neutralidad, y por eso "porque es decididamente no-neutral respecto del bien", "es ofensiva para el nuevo liberalismo"vi . Por una razón de ese tipo, por considerarla desigualitaria e 'imperialista'vii, algunos se oponen a la tolerancia. La tolerancia implica la distinción entre bien y mal - cosa poco digerible para nuestra mentalidad postmoderna-, e implica además que quien tolera se arroga la capacidad de distinguirlos y aplicar la distinción a la persona tolerada. Ciertamente, es preciso distinguir el bien del mal, o lo correcto de lo incorrecto, o al menos lo que aprobamos de lo que desaprobamos. La tolerancia no es relativista y no puede dejar de partir de la base de esa distinción, o al menos de que seamos razonablemente capaces de percibirla.

Debe notarse que no hay nada de anticonstitucional ni antidemocrático en distinguir el bien del mal (por lo menos, hasta donde seamos capaces), distinción inevitable que incluso los defensores de la neutralidad y el procedimentalismo, como Rawls, practican. Y la democracia se originó en ambientes donde el bien y el mal se distinguían. En la práctica el problema es mucho menor, pues si nosotros, la gente, no distinguimos mínimamente el bien del mal, acabarán definiéndolos (y tal vez imponiéndolos) el legislador, los tecnócratas de la Unión Europea, los altos tribunales internacionales, los medios de comunicación o la industria del entretenimiento. Y entonces tendremos una definición de bien/mal más unilateral y artificiosa que la visión popular, pues ésta siempre habrá sido el resultado de un largo proceso y de unas visiones éticas socialmente compartidas durante siglos o decenios, por lo que no habrá sido creada por ninguna persona o grupo unilateralmente, ex novo, en un sólo acto, como dictar una ley.

Tercero. Lo que se tiene o disfruta por tolerancia no se tiene por derechos o libertades. Es cierto, pero siempre habrá una zona de penumbra en la cual determinados actos o pretensiones no sean propiamente derechos pero, por las razones que sea, no serán prohibidas o descalificadas. Lo contrario lleva al maniqueísmo antes mencionado: que las pretensiones que no son derechos formales, no existen para el 
Derecho; son jurídica (y, últimamente, también socialmente) irrelevantes. Hace falta, entonces, hilar fino y evitar el vulgarismo jurídico simplificador, pero la empresa no es fácil porque vivimos en plena época de vulgarismo jurídico.

Si a pesar de que la ley ordene $X$, en la práctica hacemos por tolerancia siempre $\mathrm{Y}$, el día que el legislador quiera poner en vigor $\mathrm{X}$, la tolerancia puede ser incapaz de impedírselo, al no haber generado un derecho subjetivo a continuar con Y. Este tema merece un poco más de consideración.

\section{Tolerancia y derechos}

¿Podría la tolerancia ser contraria a los derechos? Hagamos una pregunta comparable: ¿es la compasión enemiga de la justicia? A nadie le gusta que se le conceda por compasión lo que se le debe por justicia, pero al mismo tiempo, a nadie le gusta ser tratado sólo con justicia: no recibir nada que no sea de justicia, ni los 'buenos días' en el ascensor. Ese aspecto - condescendencia, concesión, gracia, benevolencia $\mathrm{y}$, siempre, ausencia de exigibilidad jurídica-, hace a algunos autores ser críticos con la tolerancia.

En cuanto a los derechos, hay que hacer distinciones, porque hoy hay muchos derechos y diversas maneras de verlos. Los fundamentos de los derechos - vida, dignidad, libertad profunda, igualdad profunda - no chocan con la tolerancia, y algunos, como la dignidad humana y la igualdad profunda, figuran entre sus requisitos. En general, los derechos de 'primera generación' y 'verticales' (derechos frente al estado), como no ser condenado sin ser juzgado o la inviolabilidad del domicilio, por mucho que crezcan y se perfeccionen no chocarán con la tolerancia. En cambio, los derechos de hoy, los derechos de la cultura jurídica que Glendon llama Rights Talk ${ }^{v i i i}$, pueden ser negativos para la tolerancia. Varios caminos pueden conducir ahí.

El primero es el paso de la verticalidad a la horizontalidad: cuando los derechos fundamentales pasan a ser eficaces contra terceros, mejoramos en algunos aspectos, pero corremos el riesgo de acabar en pie de guerra unos contra otros; el nieto contra el abuelo, el estudiante contra el profesor o el paciente contra su médico.

El segundo es la especificidad de la última generación de derechos, muchos de los cuales son de la personalidad. No actúan en el foro o ágora sino en el interior de la persona y afectan incluso a su identidad, con lo que disminuye la posibilidad de que los veamos como algo exterior o en lo que se puede ceder. Esa exasperación puede verse, por ejemplo, en algunas pretensiones de algunos grupos feministas, como Femen.

El tercero es la penetración de los nuevos derechos, que producen la criminalización no sólo de la acción sino de la expresión, e incluso, tal vez, de la intención (apología del terrorismo, hate speech, hate crimes). Basta emparentar esto con la corrección política para aumentar la intolerancia hacia el discrepante y el políticamente incorrecto.

El cuarto es su expansividad: los derechos de la personalidad, por ser de la personalidad, definen modelos antropológicos que deben universalmente aceptados como bona fide rights, e incluso ser impuestos. No se pretende sólo que no sean perseguidos sino, positivamente, que sean asumidos por todos. Algunos comités de la ONU y, en menor medida, la UE, tienen experiencia de esto y parecen buscarlo. Ejemplo: si la ideología de género es correcta, debe ser aceptada por todos, como una base indiscutida, como no se discute el due process of law, e incluso enseñada a los niños. Estos derechos no producen una actitud de "vive y deja vivir", sino de "confórmate al modelo diseñado por la mayoría" (en la práctica, por el gobierno, los lobbies o los burócratas internacionales). 


\section{Tolerancia y derecho}

Aunque ciertamente afecte al Derecho, la tolerancia no es un concepto jurídico como el usufructo o el dominio público. Intentar captarla por medio del Derecho sería como intentar coger agua con un cesto, pues ninguna ley, constitución ni tratado internacional puede captarla, y además no es exigible ante un juez. Con todo, por un lado, incluso los cestos retienen algo de agua, y, por otro, el derecho es mucho más que ley. Si confrontamos la tolerancia con las diferentes fuentes del derecho, una por una, vemos que la relación que tiene con unas y otras varía mucho. La tolerancia es por un lado prejurídica (pues es una actitud humana básica) y por otro postjurídica, pues entra en función cuando el Derecho ya ha hablado, mitigando la dureza de su aplicación o volviendo la cabeza para otro lado.

La relación de la tolerancia con la ley no es cómoda porque la tolerancia se compadece mal con la norma abstracta y de necesario cumplimiento, y choca con ambos rasgos. El legalismo provoca intolerancia, como estamos viendo con motivo de la crisis financiera en la UE: al penetrar en la sociedad la mentalidad legalista, la tolerancia en muchas personas ha disminuido.

$\mathrm{Ni}$ la mejor norma jurídica puede captar plenamente ni definir satisfactoriamente la tolerancia. Ello, además, no tendría demasiado sentido, porque la tolerancia implicará a menudo quedarse más acá o ir más allá de la norma, o bien no cumplirla, o sólo a medias, o interpretarla con una benevolencia no prevista por el legislador. Desde el momento en que la tolerancia por definición puede implicar incumplir la ley, amortiguar sus efectos o interpretarla de otra forma, mal podrá basarse en la ley, norma general que nunca prevé su propio incumplimiento. En último extremo, sería más coherente negar la tolerancia que admitirla pero sometida a la ley, pues los derechos, pretensiones o planteamientos que de alguna forma conlleven no sometimiento a la norma, no podrán basarse en la misma norma, como se ve con particular claridad en otra figura, la objeción de conciencia (es más coherente negarla que admitirla pero dentro de la ley; aunque puede ser práctico que la ley la reconozca).

La relación de la tolerancia con la jurisprudencia puede ser fructífera porque se compadece bien con la consideración de cada caso, de cada pena, de cada sanción administrativa. La tolerancia muchas veces (no siempre) implica una buena dosis de casuismo. La tolerancia no es una pretensión jurídica directamente exigible ante un juez (en ese caso, sería un derecho), pero el juez al sentenciar tiene mucho campo donde practicarla. El juez puede ver que summum ius, summa iniuria, que la justicia total no existe o que la ley no cubre todos los casos.

En cuanto a su relación con la equidad, la costumbre y los principios, como ya dijimos, la tolerancia se encuentra cómoda.

En cambio, su relación con los valores es más problemática. Ciertamente, la tolerancia puede ser considerada como un valor, una buena meta; lo que ocurre es que, en general, no está claro que los valores sean una verdadera fuente del derecho. Añádase que su indefinición y carácter positivo (deben ser "propugnados" ${ }^{\text {, }}$, y a veces incluso impuestos) plantean problemas al Derecho, y, aunque sean objetivos buenos, si se imponen dejan poco sitio a la tolerancia. Sin duda, hay que fomentar la tolerancia, que es una excelente meta, pero no está claro que la mejor manera de hacerlo sea proclamándola formalmente como 'valor' en una constitución o tratado internacional. Por eso, la tolerancia ayuda a romper un defecto importante de nuestra actual cultura jurídica, el dualismo que no admite sino ley positiva o nada, y que tiene un paralelismo en los derechos cuando no se admite sino derechos subjetivos o nada. La historia del derecho muestra que el dualismo 'o ley o nada' nunca tuvo fundamento serio - basta repasar las fuentes del Derecho según los romanos o los anglosajones ${ }^{\mathrm{x}}$-, 
pero con el constitucionalismo positivista, ese planteamiento tomó fuerza y hoy puede verse en la mentalidad de no pocas facultades de Derecho españolas, portuguesas e países iberoamericanas, donde frecuentemente se habla se lenguaje de 'ley o nada' tomándolo de los libros más que de la vida real.

En cuanto al dualismo 'o derechos fundamentales o nada', también dañino para la tolerancia, recordaremos una frase ingeniosa anterior a la caída de la Unión Soviética y usada para caracterizar a diversos países europeos según su relación entre libertad y ley: "En Inglaterra, todo lo no expresamente prohibido está permitido; en Francia, todo lo legalmente permitido está permitido; en España, todo lo no prohibido es obligatorio, y en la Unión Soviética, todo está prohibido".

Dejando aparte el efectismo de esa ingeniosidad, detengámonos en España. Aproximadamente eso es lo que está sucediendo con la ideología de género y otros capítulos de la corrección política: su aceptación se ha vuelto obligatoria y puede ocurrir que a los discrepantes no siempre se les aplique la tolerancia. En cuanto al matrimonio homosexual, lo que ha hecho la reciente reforma es que en vez de admitir varios tipos de matrimonio (homosexual, heterosexual, disoluble, indisoluble, poligámico, monogámico), la manera de permitir a los homosexuales contraer matrimonio ha sido creando un único tipo de unión basado en lo que puede ser contraído por ellos; una especie de 'one size fits all'. No se puede contraer un matrimonio heterosexual porque en el ordenamiento jurídico español eso ha dejado de existir; sólo hay un pacto de afecto entre cualquiera, y disoluble más fácilmente que un contrato con la compañía telefónica. Al no practicarse una política de tolerancia dejamos ahora aparte la justicia-, la ideología de género ha pasado de no reconocida a obligatoria por ley en todos los niveles educativos. (Aun así, todavía queda espacio para la tolerancia si, por ejemplo, los inspectores no inspeccionan demasiado los colegios, o no revisan mucho el contenido de todas las clases que se dan en una Universidad).

Ciertamente, una ley injusta puede también ser aplicada de manera laxa y tolerante por jueces y funcionarios, pero el pastor protestante sueco Ake Green en 2004 fue condenado a pena de prisión (luego recurrida con éxito ante el Tribunal Supremo) por decir en un sermón que el matrimonio homosexual no es admisible. No menos conocido fue el caso de unos cincuenta padres de familia alemanes, luteranos, que entre 2006 y 2011 sufrieron cortas penas de prisión por oponerse a la educación sexual impuesta a sus hijos. La explicación no es que el pastor Green y los padres alemanes toparan con unos funcionarios o policías particularmente intolerantes -que puede ser - sino que los nuevos derechos son como códigos éticos (por tanto, imponen deberes) y son expansivos, tendiendo a la obligatoriedad. La perspectiva de género parece haber adquirido el status de una base ético-cultural común que no se discute y ha de ser impartida en todos los centros y a todos los alumnos ${ }^{\mathrm{xi}}$. Los nuevos derechos no definen espacios exentos de la interferencia estatal, sino modelos antropológicos que todos debemos admitir y que eventualmente el estado nos pueden imponer. "La libertad [hoy] significa control general de la relaciones humanas, para que nos oprimamos uno a otro"xii.

En general, la tolerancia está más cómoda con una visión negativa del Derecho (y también, por lo que acabamos de decir, de los derechos) que con una visión positiva, pues muchas veces implicará no ejecutar los mandatos positivos de las leyes, no seguir las metas generales de toda la comunidad política, no aceptar todo lo que se puede derivar, como por un goteo lógico, de la propia Constitución... Por lo mismo, no está cómoda con una visión piramidal del Derecho, con una visión de las constituciones que convierte al ordenamiento jurídico en mero desarrollo de las mismas, ni siquiera con una visión del Derecho como sistema y ordenamiento, pues la tolerancia puede ser imperfecta, fragmentaria y no siempre coherente. 
$\mathrm{Si}$ queremos una cultura jurídica favorable a la tolerancia es importante también distinguir el Derecho del cumplimiento y ejecución del mismo (en particular, la ley y la sentencia, que pueden verse incumplidas incluso siendo buenas leyes y buenas sentencias). La tolerancia no deroga la ley, ni recurre contra la sentencia; simplemente, no las cumple o mitiga algunos de sus efectos ante determinada situación. Nuestros antepasados practicaban la dispensatio o relaxatio legis poenalis (que no es derogación, sólo dispensa de sus efectos) y los indultos, que tampoco derogaban la ley. También admitían una categoría de leyes, las mere poenales, generadoras de una obligación menor y distinta ${ }^{\text {xiii. }}$ Eran más flexibles que nosotros.

Derecho y tolerancia son cosas distintas, pero el Derecho puede serle más o menos favorable. Una cultura jurídica favorable a la tolerancia verá al Derecho como imperfecto y conflictivo, no porque produzca conflictos, sino por verlo como un repertorio de soluciones prudenciales para casos de conflicto, como dijo en muchas ocasiones y bajo diversas formas el gran jurista compostelano Alvaro d'Ors. El Common Law parte de la imperfección y de que habrá conflictos, y por tanto hay que prever las soluciones. Por el contrario, el actual legislador español gusta de hacer leyes perfectas (de ahí el hábito de consultar profesores e imitar las normas de los países considerados más adelantados). Una vez hechas, su actitud es esperar que se cumplan, para luego sorprenderse en cuanto comienzan los fallos. Con particular claridad se ve esto en el derecho constitucional, pues más de una constitución española ha pretendido ser lo más perfecta posible, no dejar nada al azar y — la de 1978 - ser fuente y controladora de toda la ulterior producción jurídica, con la consiguiente desilusión en cuanto se producen los primeros incumplimientos, agravados hoy por el incumplimiento generalizado y la impotencia de una Constitución (por lo demás, no mala) ante el terremoto político y económico del último decenio. El contraste con la Constitución norteamericana no puede ser mayor, pues es muy deficiente técnicamente y deja muchos asuntos sin tocar, pues sus redactores la quisieron así.

\section{La Declaración de la UNESCO de 1995}

En los instrumentos jurídicos no abundan las definiciones conceptuales de la tolerancia. Hasta la Declaración de Principios sobre la Tolerancia de la UNESCO (16 de noviembre de 1995), no se intentó plasmarla en un documento internacional importante. Véase el art. 1:

"Artículo 1. Significado de la tolerancia.-1.1 La tolerancia consiste en el respeto, la aceptación y el aprecio de la rica diversidad de las culturas de nuestro mundo, de nuestras formas de expresión y medios de ser humanos. La fomentan el conocimiento, la actitud de apertura, la comunicación y la libertad de pensamiento, de conciencia y de religión. La tolerancia consiste en la armonía en la diferencia. No sólo es un deber moral, sino además una exigencia política y jurídica. La tolerancia, la virtud que hace posible la paz, contribuye a sustituir la cultura de guerra por la cultura de paz.

1.2 Tolerancia no es lo mismo que concesión, condescendencia o indulgencia. Ante todo, la tolerancia es una actitud activa de reconocimiento de los derechos humanos universales y las libertades fundamentales de los demás. En ningún caso puede utilizarse para justificar el quebrantamiento de estos valores fundamentales. La tolerancia han de practicarla los individuos, los grupos y los Estados.

1.3 La tolerancia es la responsabilidad que sustenta los derechos humanos, el pluralismo (comprendido el pluralismo cultural), la democracia y el Estado de derecho. Supone el rechazo del dogmatismo 
y del absolutismo y afirma las normas establecidas por los instrumentos internacionales relativos a los derechos humanos.

1.4 Conforme al respeto de los derechos humanos, practicar la tolerancia no significa tolerar la injusticia social ni renunciar a las convicciones personales o atemperarlas. Significa que toda persona es libre de adherirse a sus propias convicciones y acepta que los demás se adhieran a las suyas. Significa aceptar el hecho de que los seres humanos, naturalmente caracterizados por la diversidad de su aspecto, su situación, su forma de expresarse, su comportamiento y sus valores, tienen derecho a vivir en paz y a ser como son. También significa que uno no ha de imponer sus opiniones a los demás".

Aun reconociendo el esfuerzo de sus redactores, con una visión realista, el juicio sobre este instrumento jurídico internacional no puede ser muy favorable. Aparentemente, lo contiene todo, pero, acercando la lupa, varias de sus cláusulas tienen escaso contenido real (así, 1.3) Este tipo de declaraciones poco menos que inanes son responsables de que los niños, tras estudiarlas en las escuelas, acaben pensando que ser tolerante es, genéricamente, algo así como ser amable. El párrafo 1.1 dice que la tolerancia consiste en... todo (exigencia moral, política y jurídica; no aclara cómo será esta última). Nosotros entendemos que este tipo de declaraciones hacen más daño que provecho a la tolerancia porque por un lado, no la captan, y por otro, la devalúan. Aquí aparece ensalzada y simultáneamente devaluada al nivel de la buena educación, todo ello en palabras solemnes pero de poca substancia.

\section{Condicionantes}

Mientras unos factores y actitudes forman un caldo de cultivo favorable a la tolerancia, otros le son desfavorables. Intentaremos identificarlos.

Factores favorables a la tolerancia:

-visión personalista: se tolera a las personas más que a las ideas, acciones o instituciones; uno nunca tolerará el canibalismo, pero quizá tenga que tolerar a un caníbal (o, mejor, a un ex-caníbal);

-razonable confianza en la naturaleza humana; hoy estamos en el posthumanismo que, al contrario, pretende superarla - y la confianza en el hombre escasea; el propio estado confía más en las máquinas que en sus funcionarios;

- junto con esa confianza, partiremos de una inevitable dosis de imperfección humana ${ }^{\text {xiv }}$;

-en particular, asumimos la imperfección e insuficiencia de la ley y de la jurisdicción, con razonable lugar para la casuística;

—visión del Derecho: más bien negativo (prohibir más que ordenar, y prohibir lo menos posible) y con notable papel de la jurisprudencia, la equidad y los principios;

- respeto a la dignidad del hombre, de todo hombre, pues incluso delincuentes y caníbales siempre conservan un inamisible resto de dignidad;

—concepción de la libertad y de las libertades como "vive y deja vivir";

- juzgar; tener convicciones; de forma que unas cosas estarán bien y otras mal, y unos juzgarán las acciones de otro y las encontrarán buenas, malas, erróneas o desaprobables, y sin embargo se abstendrán de impedirlas o al menos desviarán o suavizarán el castigo. La neutralidad total no es un ideal, pero además no beneficia a nadie más que a quien la administra. 
Factores desfavorables: aproximadamente son como volver los anteriores como un guante:

- perfeccionismo; se reprochaba al perfeccionismo ser cosa de los aristotélicoescolásticos (la vida buena), pero ahora hay otro perfeccionismo tecnocrático y económico, tan perfeccionista como el otro pero sin su elevación moral y política. Ejemplos: eliminar todo fraude fiscal, toda la economía sumergida, todo accidente de tráfico, toda discriminación,... Nada de eso puede conseguirse a este lado de la eternidad, como no se puede conseguir eliminar toda la estupidez o todo el odio, pero su mero intento nos pone en camino hacia el totalitarismo. El jurista realista sabe que hasta la mejor constitución tiene fallos y que la ley nunca se cumplirá al cien por cien - y afortunadamente, a veces-;

- el Derecho legalista; hoy, nuestros estudiantes traen el legalismo de casa; la frase 'la ley es la ley, y es para cumplirla' es moneda corriente ${ }^{\mathrm{xv}}$;

— preferir la abstracción a la consideración de cada caso;

- los derechos de la personalidad, que nos piden "confórmate a un modelo humano o ético" acordado, en teoría, por la mayoría;

- la corrección política, en sus muy diversas manifestaciones: tabaco, impuestos, velocidad, tal vez mañana la obesidad o el azúcar...;

- la desconfianza en el hombre;

—el miedo; el no aceptar que siempre habrá un mínimo de riesgo e inseguridad;

-relativismo; hoy hay más relativismo que nunca y sin embargo la intolerancia crece $^{\text {xvi }}$;

-algunos otros aspectos de la posmodernidad: las diversas maneras de condicionar nuestro comportamiento, como nudging, choice architecture y similares. Igualmente es negativa la política de la identidad y el reconocimiento, no porque no tengamos identidad, sino porque esta política no se conforma con respetar o tolerar sino que nos pide asumir y celebrar todas las identidades como buenas. Es también muy intolerante la cada vez más extendida política de gobernar the hearts and minds de la gente, aunque sea para combatir el terrorismo.

\section{Tolerancia y relativismo}

Aquí es preciso detenernos un momento. Por un lado, queda dicho que la tolerancia no procede de nuestra incapacidad de juzgar, sino, al contrario ${ }^{\text {xvii }}$. Por otro, para muchas personas, hoy, tolerancia implica relativismo, que en algunos autores sería contrapesado por el respeto a los procedimientos neutros y aceptados por todos. Pero la ilusión procedimentalista — la ausencia de una base ética clara y compartida será compensada por unas decisiones éticas consensuadas según los procedimientos constitucionales - , se ha revelado poco realista. En nuestra vida real, nadie pide nuestro consentimiento para modificar, difundir (o imponer) una ética como tampoco lo piden para las políticas anti-crisis; nuestras nuevas éticas nunca brotan de la gente sino de los medios, los gobiernos, los lobbies más activos o la industria del entretenimiento, que pueden llegar a imponerla a unos pueblos cuya primera preocupación es, en realidad, el desempleo y la crisis económicaxiii. Así, el procedimentalismo no nos ha dejado en manos de un poder público democrático pero realmente neutro y respetuoso con las reglas que nos hayamos dado todos, sino de unos poderes políticos, económicos o culturales que saben muy bien lo que quieren, tienen sus propias visiones y las difunden. Cuando llega la crisis financiera, el poder real muestra poco respeto por esos procedimientos y reglas —incluso las de la UEteóricamente aprobadas por todos. 
Según Gray, la experiencia americana de creciente división social desde mediados de los 60, "fundada en la convicción ilustrada de que la cultura común no es una condición necesaria previa de una sociedad civil liberal, muestra que la visión de que la paz civil puede conseguirse por la adhesión a unas reglas abstractas es meramente una ilusión"xix. Es el problema del acuerdo fundamental y el procedimental, al que nos remitimos ${ }^{\mathrm{xx}}$. Pero aunque lamentemos la pérdida del anterior acuerdo fundamental y la erosión intencionada a que ha sido sometido, el hecho es que hoy muchas sociedades occidentales, parecen haberlo perdido, y por su propia naturaleza no es cosa que se pueda resucitar, ni formular en un laboratorio e imponer por fiat. ¿Qué hacer, entonces?

El procedimentalismo, por definición, no es lo mejor para la tolerancia, pero tampoco puede ser descartado por completo. En 1998 escribía Paulo Cunha ${ }^{\text {xxi. }}$

"E os bens jurídico-penais acabam por ser aqueles que os penalistas retiram[...] da ordem constitucional vigente, já que, nâo podendo pautar-se, numa sociedade pluralista e rondar o anómico, por autónomos valores de pura axiología, têm de arrimar-se ao apoio constitucional".

En la realidad española de 2015 (los países no son todos idénticos), lo equivalente a eso no ha funcionado bien, y en primer lugar por razones bien prácticas, primera, porque, la moderna ley positiva no tiene estabilidad, y, segunda, porque no la respeta el legislador. Ante la crisis financiera, ni las leyes ni la Constitución ni los Tratados europeos nos están protegiendo; por el contrario, partes de ellas han saltado por los aires o han sido abiertamente ignorados, y abundan los ejemplos. Ante las oleadas de refugiados sirios, abundan los europeos que no respetan el Derecho europeo. En estas condiciones, la ley y la Constitución no cumplen la función de producir unas pautas convenidas que, nos gusten o no, al menos fueran sólidas y generalmente respetadas, aportando así algún sentido a la vida jurídica.

En todo caso, es propio de los juristas bajar siempre a la realidad en algún momento de la argumentación. Y en nuestra realidad, aunque la cultura sea anómica en el fondo, nuestros comportamientos son muy ordenados... porque están muy controlados. Ello no se debió a discusiones populares, ni siquiera parlamentarias, sobre lo debido y lo indebido, sino a que la red de normas administrativas, protocolos de actuación, sanciones, controles y vigilancias, es tan espesa y detallada que gran parte de nuestras acciones no pueden ser espontáneas; son conductas canalizadas y a veces casi pre-configuradas, tengan o no mucho o poco sentido.

Este problema típico de nuestro tiempo - la falta de sentido en casi todo, de la arquitectura a la pintura - repercute en el Derecho, favorecida por los vientos de neutralidad y relativismo inmoderados. Se nota en particular al aplicar la tolerancia y al interpretar los derechos humanos, hoy capaces de admitir cualquier contenido y de disminuir nuestra libertad. Cuando se trata de derechos fundamentales, antes que la fundamentalidad de los derechos debería primar fundamentalidad de su sentido en particular y del sentido en general. La tolerancia es más difícil en un mundo con poco sentido compartido socialmente. Si en la sociedad hay una general falta de sentido $-\mathrm{y}$ el inmoderado predominio de la ciencia experimental conduce a ello, pues acabará por desencantar hasta las puestas de sol—, no será fácil remediarla a base de leyes positivas y constituciones. $\mathrm{Y}$ esto sería así aunque fueran razonables, estables y generalmente respetadas, como la Constitución norteamericana, pero más aun si, como la mayoría de las restantes, lo son sólo a medias. 


\section{Referencias Bibliográficas:}

Paulo F. da Cunha, A Constituiçao do Crime, Coimbra, Coimbra Editora, 1998. -Political Ethics and European Constitution, Heidelberg, Springer, 2015.

Frank Furedi, On Tolerance. A Defence of Moral Independence, Londres y NY, Continuum, 2011.

M.A. Glendon, Rights Talk. The Impoverishment of Political Discourse, N.Y., The Free Press, 1991.

John Gray, Enlightenments's Wake. Politics and Culture at the close of Modern Age, Abingdon, Routledge, 2007.

James Kalb, Against Inclusiveness, Tacoma, WA, 2013.

A.C. Pereira Menaut, Lecciones de Teoría Constitucional, Madrid, Colex, 2010

- "Elogio de la Tolerancia (y de la Imperfección)", Mercurio Peruano 525-526 (2012-2013), 213-221.

A.C. Pereira Menaut y F. Martínez Arribas, “¿Malos Tiempos para la Tolerancia? La Intolerancia latente en los Rescates Financieros en la Unión Europea hoy", Derecho Público Iberoamericano 2 (2013), 207-236.

A.C. Pereira Menaut y C. Pereira Sáez, Teoría Política, Santiago de Compostela, Andavira, 2015.

Recebido para publicação em 05-09-15; aceito em 02-10-15

\footnotetext{
i Así, Furedi, On Tolerance. El significativo subtítulo es: A defence of Moral Independence. En realidad la tolerancia, que es muy proteica, puede surgir del pragmatismo, del egoísmo inteligente, del altruismo, del respeto y de muchas fuentes más.

ii La tolerancia es "inherently judgemental" (Gray, Enlightenment's Wake, p. 28). "Indeed — dice también Furedi-tolerance has as its presupposition the logically prior assumption of disagreement and disapproval" (Furedi, 201).

iii $I$. e., más comprometida con la libertad política que con el poder o la seguridad. Aquí partimos del liberalismo político clásico, que no coincide con el liberalismo procedimentalista postmoderno de tipo rawlsiano ni con los liberals americanos, más afines a la socialdemocracia europea.

${ }^{\text {iv }}$ En ese punto rozamos la actual transformación de la izquierda, de izquierda político-económica en izquierda de causas culturales, sexuales y lifestyles, lo que está produciendo su desaparición como contrapeso al capitalismo.

v "El hombre que va en el autobús de Clapham" (una zona de Londres) fue uno de los standards de razonabilidad que usó la jurisprudencia inglesa durante decenios. Había otros: el policía razonable, the man in the middle of the road. Eran de carácter commonsensical, así que el moderno reglamentismo, como el de la UE, en la práctica no los digeriría fácilmente.

${ }^{v i}$ Gray, p. 29. En el 'nuevo liberalismo' incluye a Rawls, Dworkin y Ackermann, entre otros.

vii De ellos, Furedi se detiene sobre todo en Tariq Ramadan, que argumenta en términos de imperialismo, y Anna Elisabeta Galeotti, autora de Toleration as Recognition (Cambridge UP, 2002) libro de título significativo en el que la tolerancia acaba por ser otra cosa diferente, el reconocimiento.

viii Glendon, Rights Talk.

ix Constitución española, art. 1.1: “...propugna como valores superiores...”

${ }^{\mathrm{x}}$ Las fuentes según Gayo son tan conocidas que no necesitan ser reproducidas (Cuatro Comentarios de las Instituciones, Comentario Primero, I,2). Las fuentes tradicionales de Inglaterra (sin contar el derecho producido por la UE ni por el Tribunal de Estrasburgo al interpretar el CEDH) eran el common law, el
} 
judge-made law, el statute law (las leyes del Parlamento), la equity, las costumbres, usos y convenciones, y los books of authority.

xi Por ejemplo, véase World Health Organization Regional Office for Europe y BZgA, Standards for Sexuality Education in Europe. A framework for policy makers, educational and health authorities and specialists, (German) Federal Centre for Health Education (BZgA), Colonia, 2010; accesible en internet.

xii Kalb, Against Inclusiveness, p. 148.

xiii No obligaban al cumplimiento pero sí a la pena. Por no obligar moralmente, no generaban culpa, pero en caso de sanción había obligación de satisfacerla. No es un concepto exento de problemas, pero ello no nos concierne ahora.

${ }^{\text {xiv }}$ Si la tolerancia no está de moda es porque estamos en una época postcristiana que no acepta que seamos criaturas imperfectas (Gray, p. 27). Aceptar la imperfección va contra la idea actual, de origen ilustrado, de que algún día desaparecerán la tragedia y la miseria (p. 28). Añadamos que hoy, el remedio de toda miseria o necesidad se encarga al estado.

${ }^{x v}$ El modelo legalista de los derechos vuelve innegociables los conflictos porque son "unconditional entitlements no susceptibles de moderación"; no permiten la negociación política, sino "sólo la victoria incondicional o la rendición" (Gray, p. 34). Con todo, nótese que no es así siempre; p. ej., el derecho a no ser condenado sin juicio previo no tiene por qué producir intolerancia. Pero esto plantea el problema de si los derechos son todos iguales o no, en el que no podemos entrar ahora.

xvi Sin una mínima base moral compartida, las decisiones se vuelven más artificiales y más 'imposiciones'. "The absence of moral clarity encourages an illiberal climate of intolerant behaviour. In a world where moralists find it difficult to differentiate clearly between right and wrong, [...] without a moral grammar, ethical guidance often has a forced and artificial character" (Furedi, 171). "Cynicism about truth claims in general, and pessimism about the status of knowledge has diminished the capacity and inclination to tolerate. One of the most disturbing expressions of this development is the reluctance to deal with normative issues in public life" (Furedi, 193).

xvii También Gray dice que la tolerancia va contra la corriente de la época porque su práctica está basada en fuertes convicciones morales (p. 28).

xviii Como la neutralidad típica de nuestro liberalismo postmoderno por definición no puede decir cuál es la buena vida, quedamos en manos de lo que Gray llama "the bien-pensant opinion of the day" (Gray, p. 30; nosotros entendemos que más bien en manos de grupos de poder).

xix Gray, p. 36. "De hecho, la idea misma de una cultura común es vista como un símbolo de opresión” (p. 38). Se refiere a los Estados Unidos, pero aquí también sucede, o al menos así se dice. La realidad en España es que, al final, existe una cultura común (incluso demasiado uniforme y poco pluralista), pero la de ahora ha sido impuesta directamente y en poco tiempo por una minoría.

xx Pereira Menaut, Lecciones de Teoría Constitucional; Pereira Menaut y Pereira Sáez, Teoría Política. Ambas obras parten del liberalismo político clásico al que nos hemos referido.

${ }^{x x i}$ A Constituiçao do Crime, p. 89. Cursivas añadidas. Que la obra trate de Derecho Constitucional y Derecho Penal aumenta su significado. Cunha no sostiene que el pluralismo cuasi-anómico nos lleve a apoyarnos en el puro procedimiento, sino en la Constitución, pero en el caso de España los procedimentalistas ven la Constitución como un acuerdo básicamente procedimental, sin importar que tenga partes incluso iusnaturalistas (art. 10.1), frente a no demasiadas sólo procedimentalistas. Cunha no es un procedimentalista; ver Political Ethics..., p. 3, "No Republic Without Vertue". 